\title{
Spectro-Structural Characterization of Chalcogenide Films Containing Cd, Te and Se
}

\section{T.M. Rajakumar ${ }^{1^{*}}$, C. Sanjeeviraja ${ }^{2}$ and R. Chandramani ${ }^{3}$}

\author{
${ }^{1}$ Department of Physics, Bharathiar University, Coimbatore, India \\ ${ }^{1}$ Department of Physics, Dayananda Sagar College of Engineering, Bangalore-560 078, India \\ ${ }^{2}$ Department of Physics, Alagappa University, Karaikudi-630 003, India \\ ${ }^{3}$ Department of Physics, Dayananda Sagar College of Engineering, Bangalore-560 078, India
}

*Corresponding Author: rajtm01@gmail.com

\begin{abstract}
Chalcogenide films find many applications in electronics as memory device, laser writer \& xerography. To tailor the property to the requirement, various compositions of $\mathrm{Cd}$, Te and Se have been deposited and characterized optically. Films have been deposited by thermal evaporation as well as by electron beam evaporation. Thermal analysis such as TGA, DTA and DSC has been carried out before deposition to ensure the composition. Dependence of Eg on the composition has been justified from (T\% data) Transmittance measurements. Drastic changes in optical property due to annealing in the range $200^{\circ} \mathrm{C}$ to $400^{\circ} \mathrm{C}$ have been investigated.
\end{abstract}

Key words: Chalcogenide, $E_{g}, T G A, D T A, D S C$, XRD, Transmittance, Annealing

\section{INTRODUCTION}

The semiconductor compounds belonging to the Cadmium Chalcogenide family such as $\mathrm{Cd} \mathrm{Se}$ Te can be advantageously used as thin poly crystalline/ amorphous films for various technical applications such as memory device, xerography, and excellent laser writer sensitivity because of their direct Eg ranging from 1.6 to $2.2 \mathrm{eV}[1,2]$. Among the various methods in use, the deposition or growth of films by thermal evaporation is simple. The method can be successfully applied to get films of many semi conducting materials. 
In the present study, to tailor the properties of the films to the requirement, various compositions of $\mathrm{Cd}$, Te, Se having the formula $\mathrm{Cd}_{\mathrm{y}} \mathrm{Te}_{\mathrm{x}-\mathrm{y}} \mathrm{Se}_{1-\mathrm{x}}$ have been deposited and characterized optically. Many of the films with the composition $0 \leq \mathrm{x} \leq 1$, and $0 \leq \mathrm{y} \leq 1$ have been deposited by vacuum thermal evaporation [3]. Other films have been deposited by electron beam evaporation [4]. In this case, before depositing the films, to make sure of the desired composition of the compounds, thermal analysis such as TGA, DTA \& DSC have been carried out. Compositional dependence of $\mathrm{Eg}$ in Cadmium Chalcogenide has been investigated through optical characterization. Some of the samples have been annealed at $200^{\circ} \mathrm{C}$ to $400^{\circ} \mathrm{C}$. Effects of annealing on optical property have been analyzed $[5,6]$.

\section{MATERIALS \& METHODS}

Commercially available glass and quartz slides were used as substrates. Substrates were first washed with chromic acid, next cleaned with detergent, rinsed with acetone and finally, cleaned with double distilled water before using. Elements $\mathrm{Cd}$, Te, Se were procured in pure form from Aldrich and are used for depositing film.

$\mathrm{Cd}_{\mathrm{y}} \mathrm{Te}_{\mathrm{x}-\mathrm{y}} \mathrm{Se}_{1-\mathrm{x}}$ thin films were deposited on glass and quartz substrates by thermal vapor deposition technique with vacuum of $\approx 10^{-5}$ torr, using 'HIND HIVAC 12A4' equipment. Tantalum boat sources were used for the evaporation of stochiometric powder of the CdTeSe ternary compound. Also thin films of $\mathrm{Cd}_{\mathrm{y}} \mathrm{Te}_{\mathrm{x}-\mathrm{y}} \mathrm{Se}_{1-\mathrm{x}}$ were deposited on glass and quartz substrates by electron beam evaporation technique at vacuum of $\approx 10^{-5}$ torr, using 'HINDIVAC $12 \mathrm{~A} 4 \mathrm{D}$ ' \& 'EBG-PS-3K' gun powder supply equipment. UV-VIS-IR studies were carried out using Micro pack DH-2000 equipment. The transmission spectra in the region $180 \mathrm{~nm}$ to 1100 $\mathrm{nm}$ has been collected and optical parameters $\alpha, \mathrm{K}, \mathrm{n}$ and $\mathrm{E}_{\mathrm{g}}$ have been evaluated. Structural analysis has been carried out by XRD and EDAX. Stylus method has been used to determine the thickness of the film.

\section{RESULTS AND DISCUSSION}

\subsection{XRD}

X-ray diffraction (XRD) is a versatile, non-destructive technique that reveals detailed information about the chemical composition and crystallographic structure of natural and manufactured materials. For all the combinations of Cd Te Se samples XRD has been taken. XRD confirms (ascertains) the amorphous nature of the sample. Amorphous nature has increased with increasing Chalcogenide content. Typical X-ray diffraction pattern of the films deposited on different substrates is given in Fig. 1(a) and Fig. 1(b). The X-ray diffraction pattern of the films, possessing various compositions, reveals that irrespective of the 
deposition method and nature of substrate, the films were found to be amorphous in nature with slight shift in $2 \theta$ values shown in Table-1 [7].

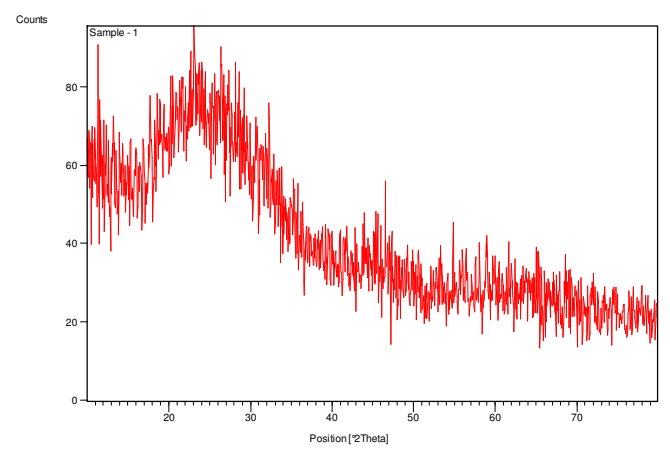

Fig. 1(a)

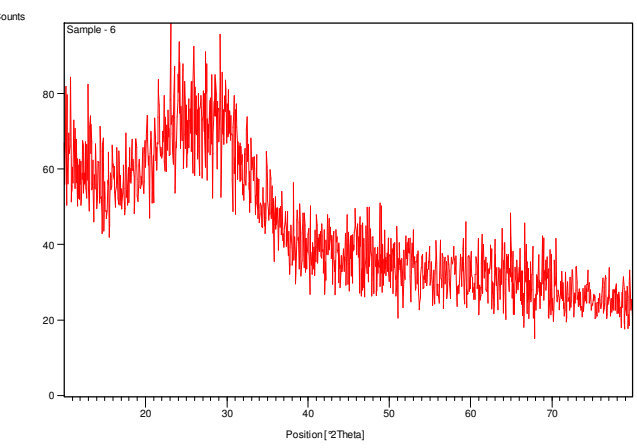

Fig. 1(b)

X-ray diffraction pattern of $\mathrm{Cd}_{0.8} \mathrm{Te}_{0.1} \mathrm{Se}_{0.1} \quad$ X-ray diffraction pattern of $\mathrm{Cd}_{0.5} \mathrm{Te}_{0.4} \mathrm{Se}_{0.1}$

Table - 1.

\begin{tabular}{|c|l|l|c|}
\hline Sl.No & \multicolumn{1}{|c|}{ Method } & \multicolumn{1}{|c|}{ Composition } & $\mathbf{2 \theta}$ \\
\hline 1 & Thermal evaporation & $\mathrm{Cd}_{0.8} \mathrm{Te}_{0.1} \mathrm{Se}_{0.1}$ & $22.5^{\circ}$ \\
2 & Thermal evaporation & $\mathrm{Cd}_{0.7} \mathrm{Te}_{0.2} \mathrm{Se}_{0.1}$ & $24^{\circ}$ \\
3 & Thermal evaporation & $\mathrm{Cd}_{0.6} \mathrm{Te}_{0.2} \mathrm{Se}_{0.2}$ & $29^{\circ}$ \\
4 & Thermal evaporation & $\mathrm{Cd}_{0.6} \mathrm{Te}_{0.3} \mathrm{Se}_{0.1}$ & $23^{\circ}$ \\
5 & Thermal evaporation & $\mathrm{Cd}_{0.5} \mathrm{Te}_{0.4} \mathrm{Se}_{0.1}$ & $29^{\circ}$ \\
6 & Electron beam evaporation & $\mathrm{Cd}_{0.6} \mathrm{Te}_{0.2} \mathrm{Se}_{0.2}$ & $23.5^{\circ}$ \\
7 & Electron beam evaporation & $\mathrm{Cd}_{0.6} \mathrm{Te}_{0.2} \mathrm{Se}_{0.2}$ & $21.5^{\circ}$ \\
& Annealed at 200 & & \\
8 & Electron beam evaporation & $\mathrm{Cd}_{0.6} \mathrm{Te}_{0.2} \mathrm{Se}_{0.2}$ & $21^{\circ}$ \\
9 & Annealed at 400 & & \\
10 & Electron beam evaporation & $\mathrm{Cd}_{0.7} \mathrm{Te}_{0.2} \mathrm{Se}_{0.1}$ & $22^{\circ}$ \\
& Electron beam evaporation & $\mathrm{Cd}_{0.8} \mathrm{Te}_{0.1} \mathrm{Se}_{0.1}$ & $23^{\circ}$ \\
\hline
\end{tabular}

\subsection{Stylus - Thickness Measurement:}

Thickness of the thin film is the most significant parameter, which plays important role in the properties of the thin film. Film thickness measurement (t) techniques are based on different principles such as the mass difference, light absorption, interference effects, conductivities, capacitance etc., of the films. Stylus method is a promising method to determine the thickness. The effect of applying a rounded stylus to thin metallic films on glass substrates has been investigated using diamond and steel styli with tip radii of approximately $25 \mu \mathrm{m}$ and loadings of up to $230 \mathrm{~g}$. In many applications, particularly in the case of the interference filters, an 
antireflection coating etc., the success of the fabrication depends only on the deposition of specific thickness of the film.

The thickness of the films was estimated to be approximately $290 \mathrm{~nm}$ to $790 \mathrm{~nm}$ using the stylus surface profilometer. Measurements have been done at two or three places. The values obtained confirm the uniformity of the film.

\subsection{TGA, DTA and DSC Analysis}

\subsubsection{TGA and DTA graphs for sample Cd $\mathrm{C}_{0.6} \mathrm{Te}_{0.2} \mathrm{Se}_{0.2}$}

While depositing the films, to ensure the desired composition $\mathrm{x}$ of the compound, TGA, DTA, and DSC studies have been carried out. TGA analysis provides a quantitative measurement of any weight changes associated with thermally induced transitions. The TGA peak for the sample is shown in Fig. 2(a).

In DTA, the difference in temperature between the sample and a thermally inert reference material is measured as a function of temperature. Any transition that the sample undergoes results in liberation or absorption of energy by the sample with a corresponding deviation of its temperature from that of the reference. The DTA peak for the sample is shown in Fig 2(a).

In DSC, the sample and reference materials are subjected to a precisely programmed temperature change. When a thermal transition occurs in the sample, thermal energy is added to either the sample or the reference in order to maintain both the sample and reference at the same temperature. Since the energy transferred is exactly equivalent in magnitude to the energy absorbed or evolved in the transition, the balancing energy yields a direct calorimetric measurement of the transition energy. The DSC peak value for the sample is $494.43^{\circ} \mathrm{C}$ [Fig 2(b)].

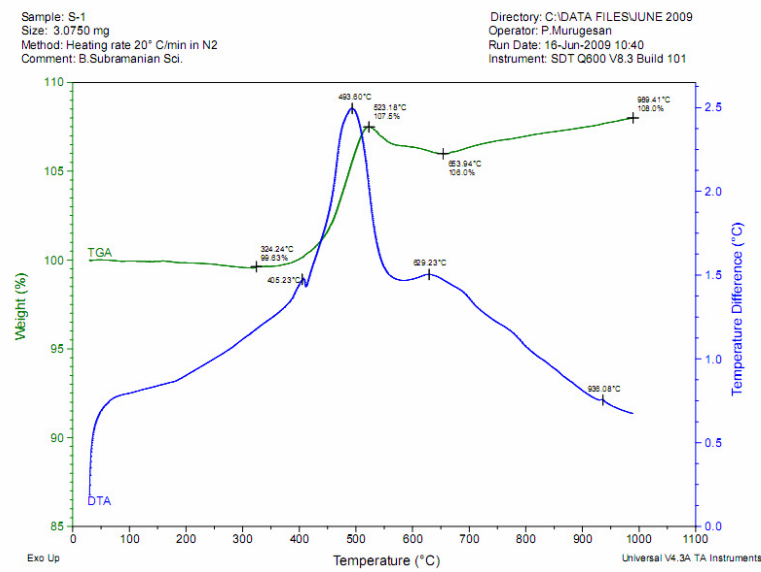

Fig 2(a)

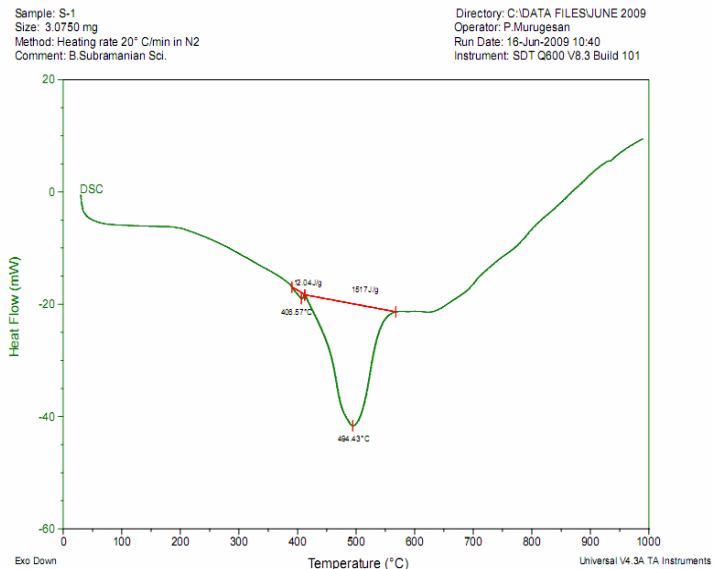

Fig 2(b)

DTA \& TGA graph for sample $\mathrm{Cd}_{0.6} \mathrm{Te}_{0.2} \mathrm{Se}_{0.2}$ 


\subsection{Optical Measurements}

Transmission spectra in the region $180-1100 \mathrm{~nm}$ has been collected using Micro pack DH-2000 equipment. The T\% were used to evaluate the optical parameters such as $\alpha, \mathrm{k}, \mathrm{n}$, and $\mathrm{E}_{\mathrm{g}}$. From Transmittance spectra, the absorption coefficient ' $\alpha$ ' has been evaluated using the formula $\alpha=\frac{2.303}{t} \log \left(\frac{1}{T}\right)$

where ' $\mathrm{t}$ ' is the thickness of the film and ' $\mathrm{T}$ ' is the transmittance percentage [2].

The value of absorption coefficient $(\alpha)$ provides valuable information about the inter band transition and hence the energy band structure of the materials.

Extinction coefficient ' $\mathrm{K}$ ' has been evaluated using the formula

$K=\frac{\lambda \alpha}{4 \pi}$

where ' $\lambda$ ' is the wavelength and ' $\alpha$ ' is the absorption coefficient.

Refractive index ' $n$ ' has been evaluated using the formula

$n=\frac{\lambda \alpha}{4 \pi k R}$

where ' $R$ ' is the reflectance percentage.

The observed values of $\lambda$, T\% and calculated values of $\alpha, \mathrm{k}, \mathrm{n}$, and $\mathrm{E}_{\mathrm{g}}$ are shown in Table- 2 . Plots of (a) T\% Vs $\lambda$ (b) $(\alpha \mathrm{h} \gamma)^{2}$ Vs Eg (Tauc plot) are shown in Figure 3(a) \& (b). Optical band gap energy has been evaluated from the Tauc plot $(\alpha h \gamma)^{2} V_{s} E_{g}$. [8].

Table -3 shows the band gap energy $\left(\mathrm{E}_{\mathrm{g}}\right)$ for different compositions. Variation of $\mathrm{E}_{\mathrm{g}}$ with composition is shown in Fig 3.4(c). Eg has increased with increase in Cd from 50\% to 70\% and has answered for decrease in $\mathrm{E}_{\mathrm{g}}$ for $80 \%$. Similar change or turning point is observed even in electrical properties [9].

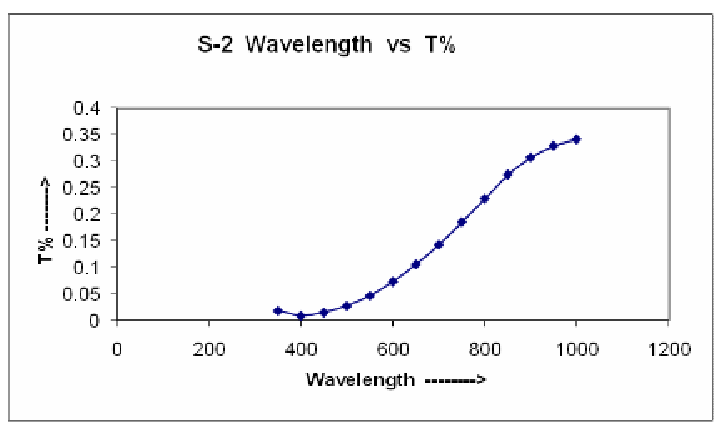

Fig 3(a)

Sample-2 Wavelength Vs T\% graph

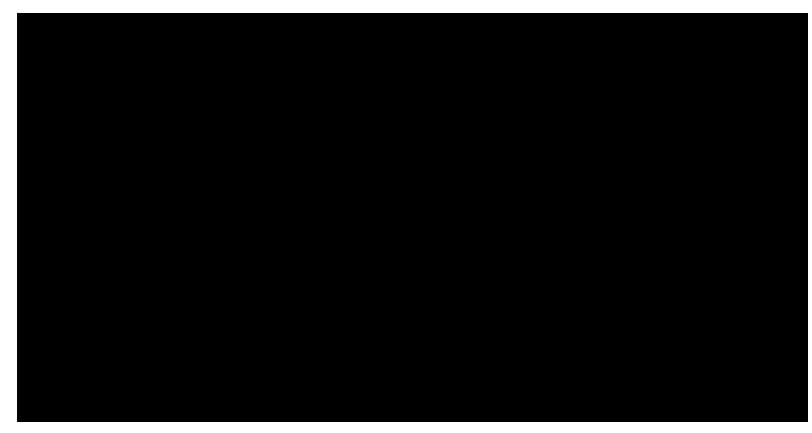

Fig 3(b)

Sample-2 Eg Vs $(\alpha h \gamma)^{2}$ graph 


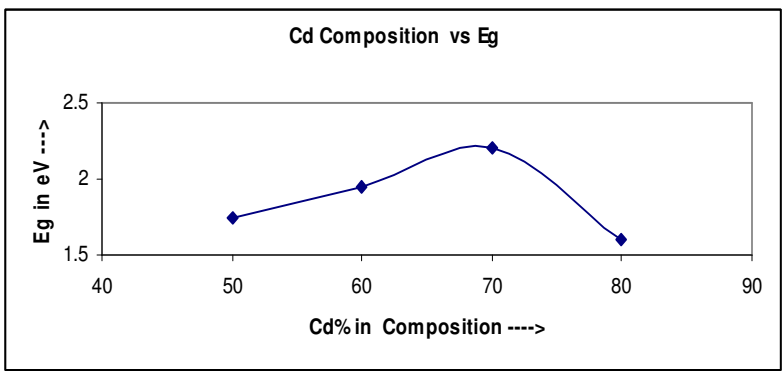

Fig 3(c)

Optical band gap vs the composition of $\mathrm{Cd}$ in $\mathrm{CdTeSe}$ graph.

Table-2

Sample-2: $\mathrm{Cd}_{0.7} \mathrm{Te}_{0.1} \mathrm{Se}_{0.2} \quad$ Thickness of the film:640 $\mathrm{nm}$

\begin{tabular}{|c|c|c|c|c|c|c|c|}
\hline $\begin{array}{l}\lambda \text { in } \\
\mathrm{nm}\end{array}$ & $\mathbf{T}$ & $\begin{array}{l}\alpha \\
\times 10^{5}\end{array}$ & $\begin{array}{l}\alpha^{2} \\
\times 10^{13}\end{array}$ & $\begin{array}{l}\mathrm{E} \text { in } \\
\mathrm{eV}\end{array}$ & $\mathbf{K}$ & $\begin{array}{l}(\alpha h \gamma)^{2} \\
\times 10^{13}\end{array}$ & $\mathrm{n}$ \\
\hline 350 & 1.82 & 62.58 & 3.91 & 3.36 & 0.174 & 44.30 & 1.01 \\
\hline 400 & 0.88 & 73.80 & 5.44 & 2.94 & 0.235 & 47.11 & 1.00 \\
\hline 450 & 1.50 & 65.54 & 4.29 & 2.61 & 0.235 & 29.36 & 1.01 \\
\hline 500 & 2.74 & 56.21 & 3.16 & 2.35 & 0.223 & 17.52 & 1.02 \\
\hline 550 & 4.66 & 47.90 & 2.29 & 2.14 & 0.209 & 10.50 & 1.04 \\
\hline 600 & 7.31 & 40.86 & 1.67 & 1.96 & 0.195 & 6.42 & 1.07 \\
\hline 650 & 10.54 & 35.15 & 1.23 & 1.81 & 0.182 & 4.05 & 1.11 \\
\hline 700 & 14.24 & 30.46 & 0.92 & 1.68 & 0.169 & 2.62 & 1.16 \\
\hline 750 & 18.50 & 26.36 & 0.69 & 1.57 & 0.157 & 1.71 & 1.22 \\
\hline 800 & 22.92 & 23.01 & 0.52 & 1.47 & 0.146 & 1.14 & 1.29 \\
\hline 850 & 27.42 & 20.22 & 0.40 & 1.38 & 0.136 & 0.78 & 1.37 \\
\hline 900 & 30.66 & 18.47 & 0.34 & 1.31 & 0.132 & 0.58 & 1.44 \\
\hline 950 & 32.85 & 17.39 & 0.30 & 1.24 & 0.131 & 0.46 & 1.48 \\
\hline 1000 & 34.07 & 16.82 & 0.28 & 1.18 & 0.134 & 0.39 & 1.51 \\
\hline
\end{tabular}

Table-3 Optical band gap energies

\begin{tabular}{|c|c|c|}
\hline Sample No & Composition & Eg in eV \\
\hline sample-1(S-1) & $\mathrm{Cd}_{0.8} \mathrm{Te}_{0.1} \mathrm{Se}_{0.1}$ & 1.6 \\
sample-2(S-2) & $\mathrm{Cd}_{0.7} \mathrm{Te}_{0.1} \mathrm{Se}_{0.2}$ & 2.05 \\
sample-3(S-3) & $\mathrm{Cd}_{0.7} \mathrm{Te}_{0.1} \mathrm{Se}_{0.2}$ & 2.2 \\
sample-4(S-4) & $\mathrm{Cd}_{0.6} \mathrm{Te}_{0.2} \mathrm{Se}_{0.2}$ & 1.95 \\
sample-5(S-5) & $\mathrm{Cd}_{0.6} \mathrm{Te}_{0.3} \mathrm{Se}_{0.1}$ & 1.95 \\
sample-6(S-6) & $\mathrm{Cd}_{0.5} \mathrm{Te}_{0.4} \mathrm{Se}_{0.1}$ & 1.75 \\
\hline
\end{tabular}




\subsection{Annealing Studies}

A sample answering for complete reflection changes to comparable $(\mathrm{R} \& \mathrm{~T})$ for annealing at $200^{\circ} \mathrm{C}$. Finally it changes to complete T\% for $400^{\circ} \mathrm{C}$ annealing. Values are shown in Table -4 and Fig 4(a).

When ' $\mathrm{T}$ ' and ' $\mathrm{R}$ ' are comparable, Absorption coefficient has been evaluated using the formula [9] $\alpha=\frac{2.303}{t} \log \left[\frac{(1-R)^{2}}{T}\right]$

Effects of annealing on the optical property of the films are really surprising. Annealing of the films has resulted in drastic change in $\mathrm{R} \& \mathrm{~T} \%$. A good reflecting film has changed to comparable $\mathrm{R} \& \mathrm{~T}$ and finally to a film with good $\mathrm{T} \%$.

Another effect of annealing is drastic change in Eg has also been noticed.

Annealing the sample-7 (S-7), $\mathrm{E}_{\mathrm{g}}$ has decreased from 1.95 (S-8:1.8) to 1.75 (1.3) for $200^{\circ} \mathrm{C}$, where as for $400^{\circ} \mathrm{C}$ annealing, $\mathrm{E}_{\mathrm{g}}$ has increased to 2.65 (2.6). Band gap variation with annealing is shown in Table-(5). The plots of band gap Vs temperature is shown in Fig 4(b) and (c) for Sample-7(S-7) and sample-8(S-8) respectively.

Table - 4 Sample-7

\begin{tabular}{|c|c|c|c|c|c|c|}
\hline \multirow{2}{*}{ wavelength } & \multicolumn{3}{|c|}{ T \% } & \multicolumn{3}{c|}{ R\% } \\
\cline { 2 - 7 } & $\begin{array}{c}\text { As } \\
\text { deposited }\end{array}$ & $\begin{array}{c}\text { Annealed } \\
\text { at 200 C }\end{array}$ & $\begin{array}{c}\text { Annealed } \\
\text { at 400 }^{\circ} \mathbf{C}\end{array}$ & $\begin{array}{c}\text { As } \\
\text { deposited }\end{array}$ & $\begin{array}{c}\text { Annealed } \\
\text { at 200 }\end{array}$ & $\begin{array}{c}\text { Annealed } \\
\text { at 400 }^{\circ} \mathbf{C}\end{array}$ \\
\hline 350 & 3.21 & 42.29 & 90.45 & 96.78 & 57.70 & 9.54 \\
400 & 3.08 & 42.79 & 93.38 & 96.91 & 57.20 & 6.61 \\
450 & 4.18 & 44.82 & 94.77 & 95.81 & 55.17 & 5.22 \\
500 & 5.65 & 47.06 & 95.61 & 94.35 & 52.94 & 4.38 \\
550 & 7.23 & 49.11 & 95.60 & 92.76 & 50.88 & 4.39 \\
600 & 8.70 & 50.50 & 94.95 & 91.29 & 49.49 & 5.04 \\
650 & 9.82 & 51.00 & 94.06 & 90.17 & 48.99 & 5.93 \\
700 & 10.54 & 50.74 & 92.81 & 89.45 & 49.25 & 7.19 \\
750 & 10.97 & 50.20 & 91.15 & 89.02 & 49.79 & 8.85 \\
800 & 11.27 & 50.10 & 89.68 & 88.72 & 49.90 & 10.31 \\
850 & 11.55 & 50.52 & 89.03 & 88.44 & 49.47 & 10.96 \\
900 & 11.69 & 50.99 & 88.87 & 88.30 & 49.01 & 11.12 \\
950 & 11.70 & 51.36 & 88.39 & 88.29 & 48.63 & 11.60 \\
1000 & 11.64 & 51.75 & 87.79 & 88.35 & 48.24 & 12.20 \\
\hline
\end{tabular}




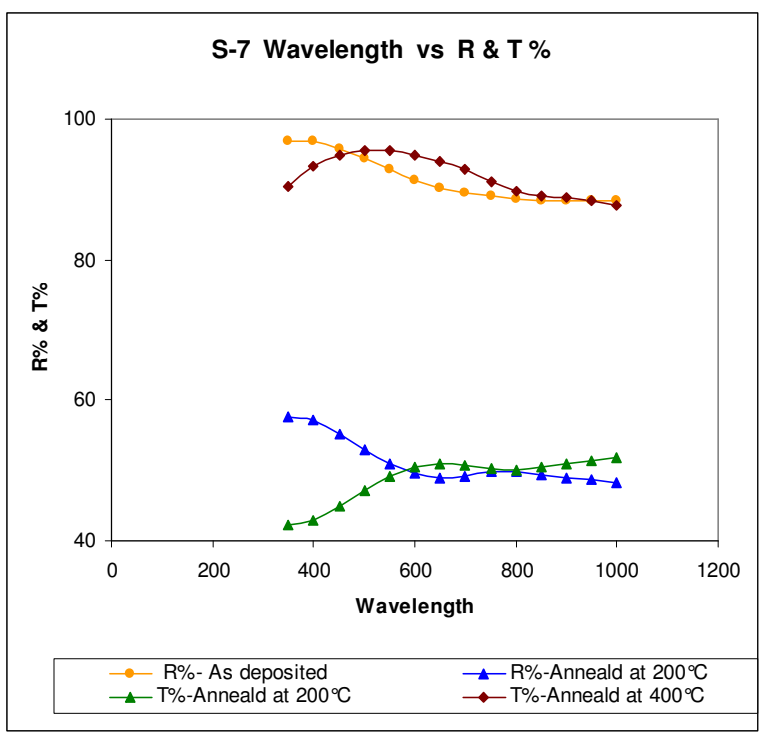

Fig 4(a)

S-7 Wavelength Vs R \& T\%.

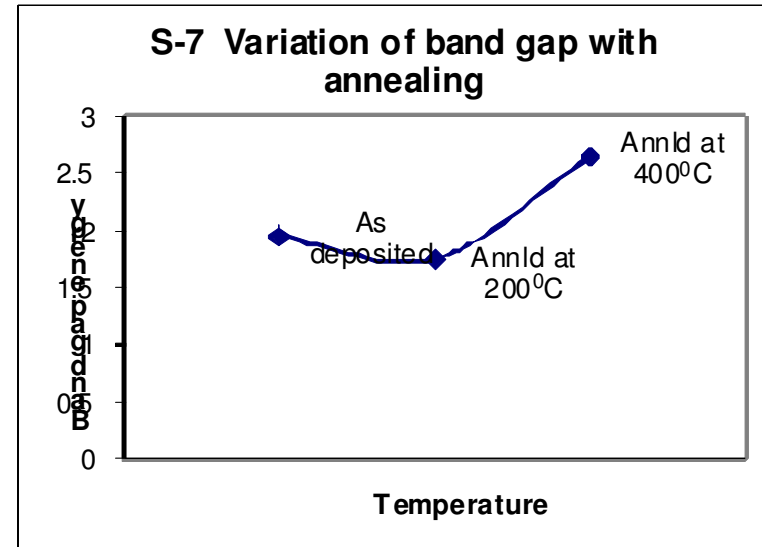

Fig 4(b)

S-7 Variation of band gap with annealing.

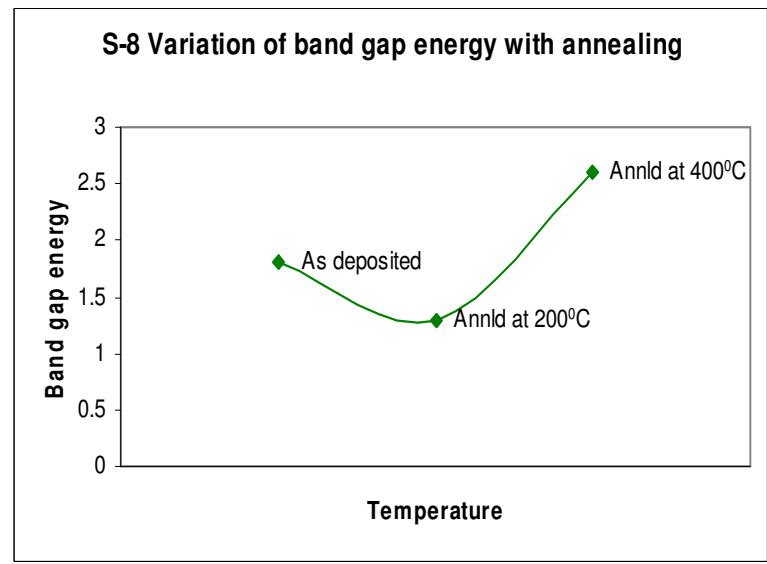

Fig 4(c)

S-8 Variation of band gap with annealing.

Table-5. Band gap variations.

\begin{tabular}{|c|c|c|c|c|}
\hline \multicolumn{5}{|c|}{ Optical Band gap in eV } \\
\hline Sample & Composition & $\begin{array}{c}\text { As } \\
\text { Deposited }\end{array}$ & $\begin{array}{c}\text { Annealed } \\
\text { at 200 }\end{array}$ & $\begin{array}{c}\text { Annealed } \\
\text { at 400 }\end{array}$ \\
\hline S-7 & $\mathrm{Cd}_{0.6} \mathrm{Te}_{0.2} \mathrm{Se}_{0.2}$ & 1.95 & 1.75 & 2.65 \\
$\mathrm{~S}-8$ & $\mathrm{Cd}_{0.7} \mathrm{Te}_{0.2} \mathrm{Se}_{0.1}$ & 1.8 & 1.3 & 2.6 \\
\hline
\end{tabular}




\section{CONCLUSIONS}

$\mathrm{Cd}$ chalcogenides for various compositions, $0 \leq \mathrm{x} \leq 1$ and $0 \leq \mathrm{y} \leq 1$ were prepared by thermal evaporation as well as by electron beam evaporation.

- XRD has confirmed the amorphous nature of the films.

- Uniformity of the films has been confirmed by Stylus measurement.

- Dependence of band gap with the composition has been justified by optical studies.

- Transmittance percentage has varied from 0.889 to 34.09 for $\mathrm{Cd}$ varying in the range $0 \leq \mathrm{x} \leq 1$.

- Increase in $\mathrm{Cd}$ has resulted in increase of $\mathrm{E}_{\mathrm{g}}$ which is a cumulative effect of the increase of $\mathrm{Cd}$ along with decrease in Se.

- Annealing at $200^{\circ} \mathrm{C}$ has resulted in decrease of $\mathrm{Eg}_{\mathrm{g}}$.

- Effects of annealing on the optical property of the films are really surprising. Annealing of the films has resulted in drastic changes in the optical properties.

- Drastic change in $\mathrm{E}_{\mathrm{g}}$ also been noticed after annealing at $200^{\circ} \mathrm{C}$ and $400^{\circ} \mathrm{C}$.

- Study reveals that slow rate changes occurring at low temperature ranges $200^{\circ} \mathrm{C}$ to $400^{\circ} \mathrm{C}$ can be used to control the optical/electrical property and finally optical band gap in a precise manner.

- Further work to confirm the exact turning point in $\mathrm{E}_{\mathrm{g}}$ is in progress.

\section{ACKNOWLEGMENT}

The authors thank Dr.Premachandra Sagar, Vice Chairman, Dayananda Sagar Institutions, Bangalore, India for his continuous encouragement.

\section{REFERENCES}

[1] R. Bhargava, Properties of wide band gap II-VI semiconductors. (1997) (INSEOSEC) publications, London.

[2] C. Baban, G.I. Rusuand Prepelita (2005) Journal of Opto Electronics and Advanced Materials Vol 7(2) pp.817-821.

[3] P.J. Sebastian and S. Sivaramakrishnan, Journal of Applied Physics, 65, 237(1989).

[4] R. Islam, H.D. Banergee, D.R.Rao, (1995) Thin Solid Films Vol.266, pp.215.

[5] Uma and R. Chandramani (2009) J. of Active and Passive Electronic Devices, Vol.8, pp.213-222.

[6] Jaan Hiie, -Article, Tallinn University of Technology, Department of Materials Science, Chair of Semi-conducting Materials Technology ,Ehitajate tee 519086 Tallinn, Estonia. Energy and Power Newsletter Vol.4 Issue 11

[7] D. Cullity, Elements of x-ray diffraction, (1959) Addison Wesley Press, London . 
[8] Tauc, J. (1968) "Optical properties and electronic structure of amorphous Ge and Si". Material Research Bulletin Vol.3: pp.37-46.

[9] T. Bhuvaneshwara Babu, R. Chandramani (2009) " Growth \& Optical Characterization of Ternary Materials", Journal of Research \& Industry, Vol. 2, pp. 91-96. 